\title{
Ottawa Heart Institute producing alternative to technetium-99 isotopes
}

Published at www.cmaj.ca on Mar. 31

I t was "more serendipity than foresight," but research commenced more than a decade ago by a team at the University of Ottawa Heart Institute in Ontario could pave the way to finding alternatives for nuclear-produced medical isotopes.

Dr. Terrance Ruddy, director of nuclear cardiology at the institute, says the team of chemists, medical physicists and researchers began looking into alternatives to technetium-99 the isotope most commonly used to treat and diagnose cancer, heart disease and other illness - long before current shortages sent medical facilities scrambling to secure supplies of isotopes. "It was more serendipity than foresight. But you can call it foresight if you want."

The institute is now at the point where it is producing an alternative isotope - rubidium-82 - in a generator "about the size of a beer fridge," Ruddy says. The isotope can be used in Positron Emission Tomography (PET) scans, which use traceable isotopes to light up organs or areas of disease. It is considered more accurate and safer because it exposes patients to less radiation.

"We wanted to be state-of-the-art for cardiac imaging," Ruddy says. "But the same methodology can also be used for cancer imaging."

The institute was also successful in obtaining funding for a cyclotron which is used to produce fluorine- 18 , which is attached to FDG to create a glucosebased radio-pharmaceutical used for PET cancer imaging and for looking at heart muscle metabolism.

Patients around the world are experiencing testing delays due to a shortage of isotopes caused by ongoing repairs at the National Research Universal reactor in Chalk River, Ontario, and the High Flux Reactor in Petter, the Netherlands.

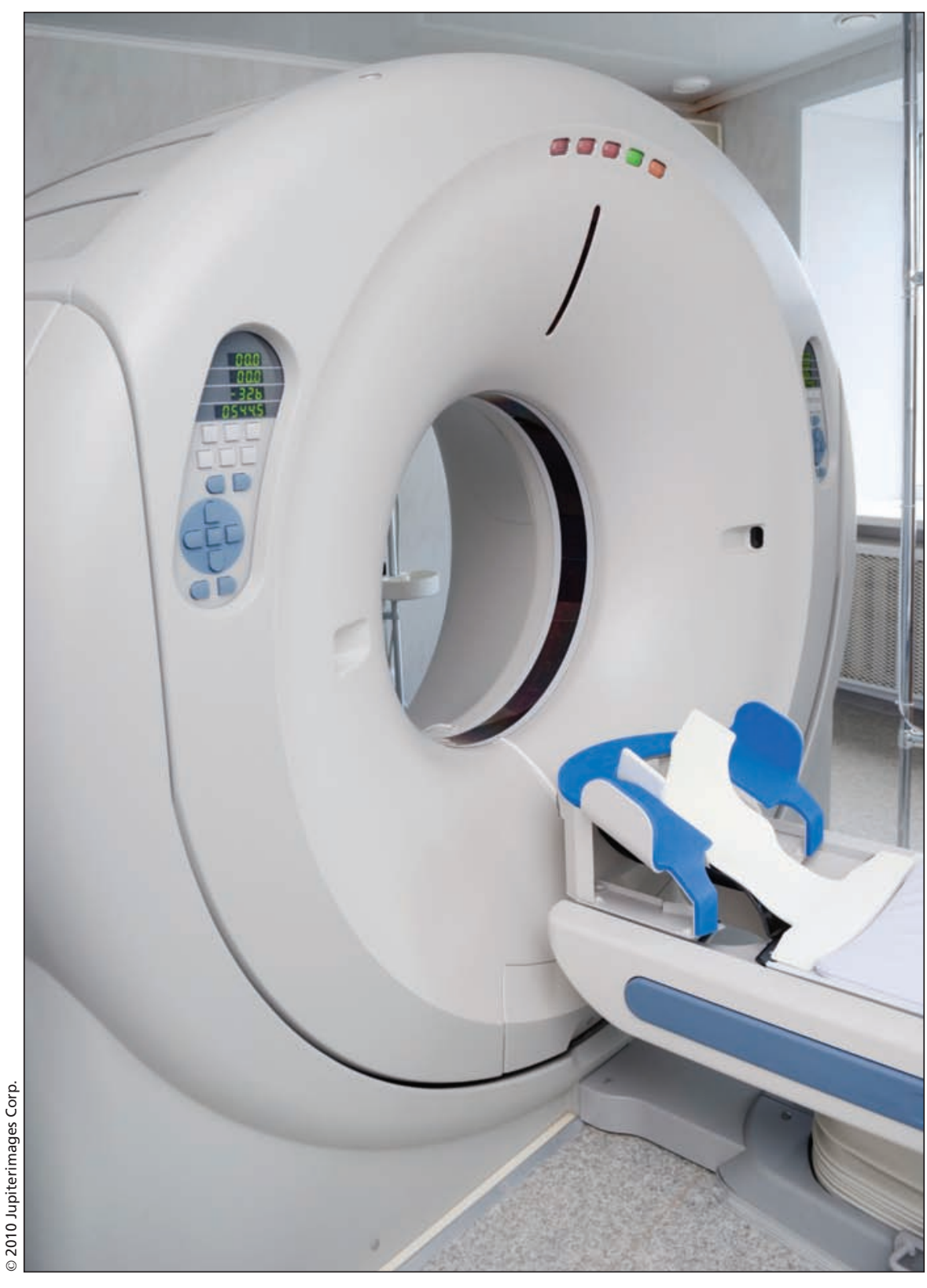

Positron emission tomography scanners can be used for diagnostic testing in the face of shortages of technetium-99 isotopes, but they're not a national solution because there aren't enough of them in Canada "to make a major dent," says Dr. Rob Beanlands, chief of cardiac imaging at the Ottawa Heart Institute in Ontario.

The Society of Nuclear Medicine warned on Mar. 18 that hospitals around the world will this summer face "one of the most significant disruptions ever," of molybdenum-99, the radioactive substance that is used to produce technetium-99m (www.snm.org/index .cfm?PageID=9584). 
But Ottawa-area residents are getting crucial diagnostic imaging tests, Ruddy says. "There are no cancer patients not getting their bone scans. It's the noncancer indication bone scans that are being redirected. We're triaging, and then recommending similar alternative tests with similar diagnostic accuracy."

Guy Morency, a spokesman for the nuclear medicine departments at five Ottawa-area hospitals, says "all urgent patients are being done. It is just those that we would deem to be more of an elective style or follow-up that needs to be confirmed. And those are getting done within one to five days."

"We can replace a lot of the technetium use with thallium (another tracer) or with our PET studies," Ruddy says. "By us giving up the technetium — and we're a large user - that meant there was more available for the rest of the community," including other area hospitals and private clinics.
Still, the situation is not ideal, says Dr. Rob Beanlands, chief of cardiac imaging at the Ottawa Heart Institute. "Nobody is being turned away and nobody is being cancelled and nobody is waiting any significantly different length of time than before this happened. But it's because we had a game plan with the thallium. We have a large cardiac volume that meant our technitium could be shifted over to the cancer folks and because of some of the research we've doing with the (single photon emission computed tomography) cameras and the PET tracers."

It's also not a national solution to isotope shortages, Beanlands adds. PET cameras are costly - about \$3 million each - and there aren't enough of them across Canada, "to make a major dent."

Canadian Society of Nuclear Medicine President Dr. Jean-Luc Urbain concurs. "Ottawa is in a totally differ- ent predicament and you cannot equate an academic centre to a community situation."

"The problem is that there are not enough PET scanners, rubidium is much more expensive and it's more labour intensive," Urbain adds. "It's very difficult to do these types of studies outside of the academic environment."

"Academically, yes, it can be done. Is it viable, socio-economically, for nonacademic centres in Canada and the rest of the world? Not yet. It's not economically feasible outside the academic setting and won't be for a long time."

Still, both Ruddy and Beanlands argue that it is "crucial" that research continue into the use of alternatives, including forms of diagnostic testing that do not involve the use of isotopes. - Becky Rynor, Ottawa, Ont.

DOI:10.1503/cmaj.109-3224 